Portland State University

PDXScholar

\title{
Towards the Rational Design of MRI Contrast Agents: Electron Spin Relaxation Is Largely Unaffected by the Coordination Geometry of Gadolinium(III)-DOTA-Type Complexes
}

\author{
Alain Borel \\ Ecole Polytechnique Fédérale de Lausanne \\ Jonathan F. Bean \\ University of Illinois at Urbana-Champaign \\ Robert B. Clarkson \\ University of Illinois at Urbana-Champaign \\ Lothar Helm \\ Ecole Polytechnique Fédérale de Lausanne \\ =olick Moriggi additional works at: https://pdxscholar.library.pdx.edu/chem_fac \\ Ecole Polytechnique Federale de Lausanne \\ Part of the Chemistry Commons \\ Let us know how access to this document benefits you.
}

\section{Citation Details}

Borel, A., Bean, J. F., Clarkson, R. B., Helm, L., Moriggi, L., Sherry, A. D., \& Woods, M. (2008). Towards the Rational Design of MRI Contrast Agents: Electron Spin Relaxation Is Largely Unaffected by the Coordination Geometry of Gadolinium (III)-DOTA-Type Complexes. Chemistry-A European Journal, 14(9), 2658-2667.

This Post-Print is brought to you for free and open access. It has been accepted for inclusion in Chemistry Faculty Publications and Presentations by an authorized administrator of PDXScholar. Please contact us if we can make this document more accessible: pdxscholar@pdx.edu. 


\section{Authors}

Alain Borel, Jonathan F. Bean, Robert B. Clarkson, Lothar Helm, Loïck Moriggi, A. Dean Sherry, and Mark Woods 


\title{
Towards the Rational Design of MRI Contrast Agents: Electron Spin Relaxation Is Largely Unaffected by the Coordination Geometry of Gadolinium(III)-DOTA-Type Complexes
}

\author{
Alain Borel ${ }^{a, b}$, Jonathan F. Bean ${ }^{b}$, Robert B. Clarkson [Prof.] ${ }^{b}$, Lothar Helm [Prof.] ${ }^{a}$, Loïck \\ Moriggia ${ }^{a}$, A. Dean Sherry [Prof.] ${ }^{\mathrm{C}, \mathrm{d}}$, and Mark Woods ${ }^{\mathrm{C}, \mathrm{e}}$ \\ aLaboratoire de Chimie Inorganique et Bioinorganique, Ecole Polytechnique Fédérale de Lausanne, \\ 1015 Lausanne (Switzerland) \\ bIllinois EPR Research Center, University of Illinois at Urbana-Champaign, Urbana IL 61801 (USA) \\ 'Department of Chemistry, University of Texas at Dallas, 2601 N. Floyd Road, Richardson, TX \\ 75080 (USA), Fax: (+1) 972-883-2925 \\ dAdvanced Imaging Research Center, University of Texas Southwestern Medical Center, 5323 \\ Harry Hines Blvd, NE 4.2, Dallas TX 75390 (USA) \\ eMacrocyclics, 2110 Research Row, Suite 425, Dallas, TX 75252 (USA) \\ Alain Borel: alain.borel@epfl.ch; Jonathan F. Bean: ; Robert B. Clarkson: ; Lothar Helm: ; Loïck Moriggi: ; A. Dean Sherry: ; \\ Mark Woods: mark.woods@utdallas.edu
}

\section{Abstract}




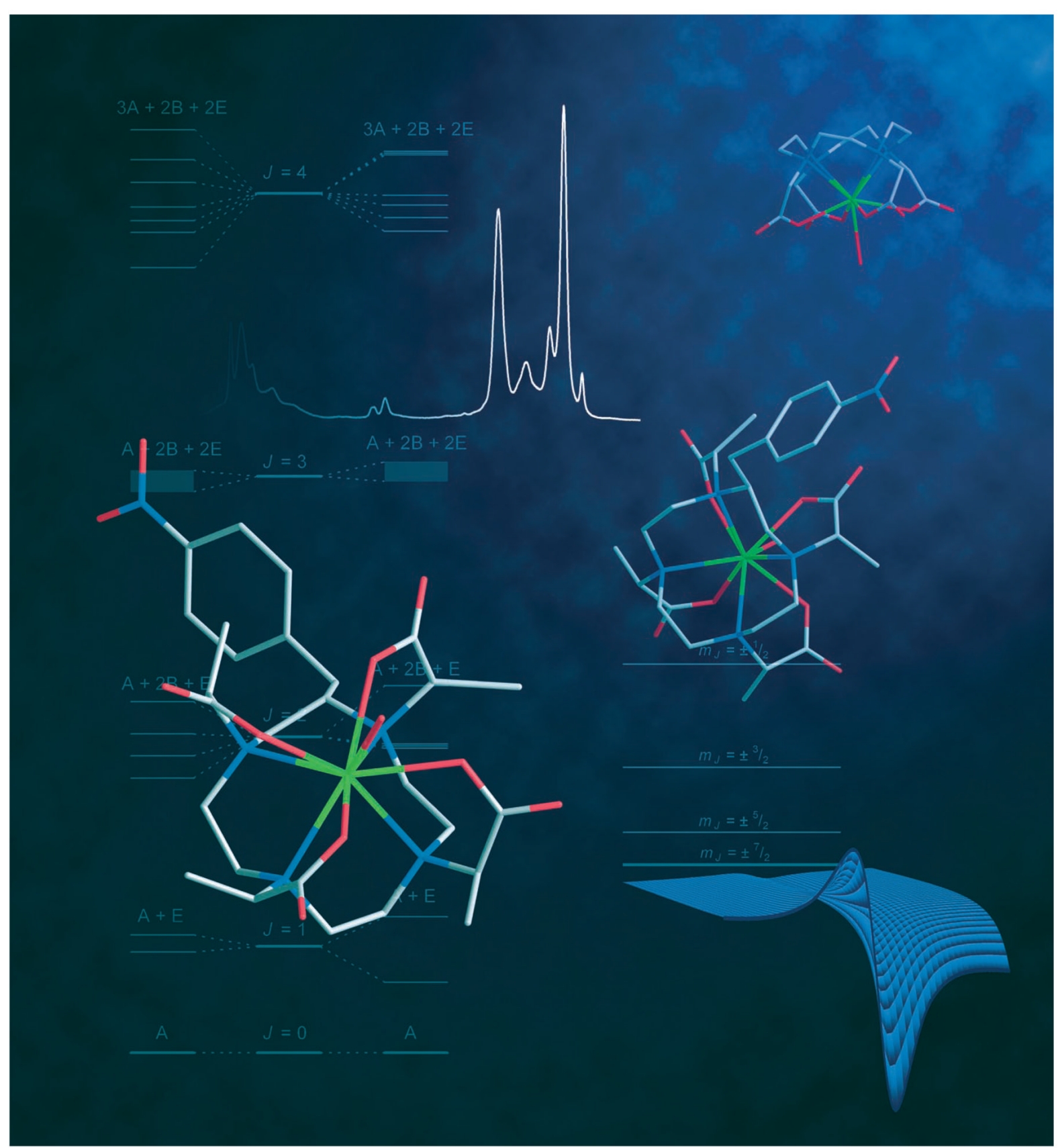

Electron-spin relaxation is one of the determining factors in the efficacy of MRI contrast agents. Of all the parameters involved in determining relaxivity it remains the least well understood, particularly as it relates to the structure of the complex. One of the reasons for the poor understanding of electronspin relaxation is that it is closely related to the ligand-field parameters of the $\mathrm{Gd}^{3+}$ ion that forms the basis of MRI contrast agents and these complexes generally exhibit a structural isomerism that inherently complicates the study of electron spin relaxation. We have recently shown that two DOTAtype ligands could be synthesised that, when coordinated to $\mathrm{Gd}^{3+}$, would adopt well defined coordination geometries and are not subject to the problems of intramolecular motion of other complexes. The EPR properties of these two chelates were studied and the results examined with theory to probe their electron-spin relaxation properties. 


\section{Keywords}

coordination geometry; EPR spectroscopy; gadolinium; imaging agents; macrocyclic ligands

\section{Introduction}

Since their introduction into clinical medicine in the early 1980s considerable effort has been devoted to the development of more effective MRI contrast agents. The efficacy of a contrast agent, typically a $\mathrm{Gd}^{3+}$ complex, is measured in terms of its relaxivity, defined as the increase in water proton relaxation rate per unit concentration of contrast agent. The theory of nuclear relaxation developed by Solomon, Bloembergen and Morgan[1-5] is commonly used to describe the parameters that influence relaxivity, three of which are commonly targeted for modification in contrast agent design in order to improve relaxivity. The hydration state of the gadolinium ion $(q)$ is readily adjusted by altering the denticity of the ligand, however, for reasons of stability $q=1$ complexes are normally preferred.[6,7] Lengthening the rotational correlation time of the complex $\left(\tau_{\mathrm{R}}\right)$ improves the coupling of electron and nuclear spins in a magnetic field and thus increases relaxivity at magnetic fields typically used in MRI (0.5-3 $\mathrm{T})$. Longer $\tau_{R}$ values are readily achieved by increasing the hydrodynamic volume of the contrast agent.[6] In order to maximize the effect of a long $\tau_{R}$ value the water residence lifetime of the coordinated water molecules $\left(\tau_{\mathrm{M}}\right)$ must also be optimized. If water exchange is too slow then water needlessly occupies the coordination site on the metal ion, preventing relaxation of other water molecules. If water exchange is too fast, however, then the water protons are not effectively relaxed before the water molecule leaves. A number of design strategies have been reported to optimize the water exchange kinetics of gadolinium complexes.[8-10] Despite these advances in the design of gadolinium-based contrast media there remains one additional parameter in the equations of Solomon, Bloembergen and Morgan[1-5] that is critical to the optimization of relaxivity; the electronic relaxation time of the gadolinium ion $\left(\tau_{\mathrm{S}}\right)$. Although one of the primary reasons for the success of $\mathrm{Gd}^{3+}$ as the basis of MRI contrast agents is its relatively long electronic relaxation time, the structural factors that govern this parameter are, as yet, not fully understood. Early work by Koenig on the gadolinium complexes of [Gd-(dtpa) $\left.\left(\mathrm{H}_{2} \mathrm{O}\right)\right]^{2-}$, $\left[\mathrm{Gd}(\mathrm{dota})\left(\mathrm{H}_{2} \mathrm{O}\right)\right]^{-}$and $\left[\mathrm{Gd}\left(\right.\right.$ dota-pa) $\left.\left(\mathrm{H}_{2} \mathrm{O}\right)\right]$, the mono-propylamide of DOTA, led to the suggestion that electron spin relaxation was primarily influenced by the symmetry and rigidity of the complex.[11,12] However, examination of the properties of some of the many complexes studied since then shows that the factors that govern electronic relaxation must be far more complex than can be accounted for in simple terms of rigidity and symmetry.

Although it is accepted that the effect of altering electronic relaxation in low molecular weight chelates is likely to be negligible at the relatively high fields at which clinic imaging is performed today, there remain several reasons to understand the factors that govern the electronic relaxation of a $\mathrm{Gd}^{3+}$ complex. Not least of these is that at the current imaging fields, $\tau_{S}$ has a limiting effect on relaxivity once $\tau_{M}$ and $\tau_{R}$ have been optimized. The primary cause of electron spin relaxation in solutions of $\mathrm{Gd}^{3+}$ complexes is modulation of the zero-field splitting (ZFS) through perturbation of the ligand field by rotation, vibration and other motions. ZFS is a consequence of inter-electronic repulsion, spin-orbit coupling and the action of the ligand field on the unpaired electrons of the $\mathrm{Gd}^{3+}$ ion. Thus, if we hope to be able to completely understand ZFS, and ultimately electron spin relaxation, a detailed appreciation of how molecular structure and dynamics affect the ZFS of $\mathrm{Gd}^{3+}$ complexes will be necessary. A recurrent problem in the study of electron-spin relaxation is the structural isomerism of $\mathrm{Gd}^{3+}$ chelates. This means that not only is there more than one species, and therefore more than one set of ligand-field parameters being studied at once, but internal molecular motion is modulating these ligand-field parameters during the experiment. Take for example [Gd(dota) $\left.\left(\mathrm{H}_{2} \mathrm{O}\right)\right]^{-}$which exists as a mixture of two coordination geometries: a monocapped square 
antiprism (SAP) and a monocapped twisted square antiprism (TSAP) in solution. These two coordination isomers interconvert at a rate on the order of $10 \mathrm{~s}^{-1}$ at room temperature.[13,14] Since $\left[\mathrm{Gd}(\mathrm{dota})\left(\mathrm{H}_{2} \mathrm{O}\right)\right]^{-}$constitutes approximately $17 \%$ TSAP and $83 \%$ SAP in solution[15] the electron-spin relaxation parameters measured for this complex are a weighted average of the actual parameters of each coordination isomer.

As part of an investigation into controlling the rate of water exchange in lanthanide complexes $[8,14,16]$ we devised a method by which the two coordination isomers of lanthanide DOTA complexes could be selectively synthesised.[8] The reason for doing this is that it was well known that the TSAP isomer exhibited much more rapid water exchange kinetics than the SAP isomer. $[8,14,17,18]$ The $S$-SSSS isomer of $\left[\operatorname{Gd}(\mathbf{1})\left(\mathrm{H}_{2} \mathrm{O}\right)\right]^{-}$, which adopts a TSAP geometry, was found to have a $\tau_{\mathrm{M}}$ value (15 ns) one order of magnitude shorter than that found for the $S$-RRRR isomer (120 ns), which adopts a SAP geometry.[8] In addition to providing a system with optimal water exchange kinetics for high relaxivities, the isolation of the two coordination geometries of [Ln-(dota) $]^{-}$complexes also afforded a unique opportunity to study the electronic relaxation properties of each of these structurally distinct complexes, SAP and TSAP, not only in isolation but also in the absence of the processes by which the two isomers interconvert. The method of choice for investigating electron spin relaxation is electron-paramagnetic resonance (EPR) spectroscopy. Given the number of variable temperature and/or frequency studies performed over the last decade[19-22] the amount of experimental data available to researchers has recently increased significantly and this has led to more refined theoretical models for the treatment of this type of data. The EPR properties of the two complexes [Gd(S-SSSS-1)

$\left.\left(\mathrm{H}_{2} \mathrm{O}\right)\right]^{-}(\mathrm{TSAP})$ and $\left[\mathrm{Gd}(S-R R R R-\mathbf{1})\left(\mathrm{H}_{2} \mathrm{O}\right)\right]^{-}(\mathrm{SAP})$ were assessed to investigate whether these systems might begin to provide useful information relating the structural parameters of $\mathrm{Gd}^{3+}$ complexes to their electron-spin relaxation properties. 


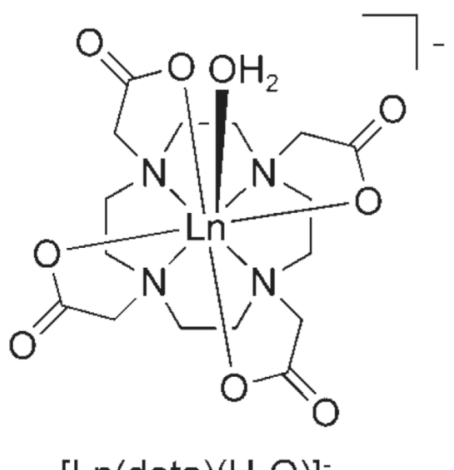

$\left[\mathrm{Ln}(\operatorname{dota})\left(\mathrm{H}_{2} \mathrm{O}\right)\right]^{-}$

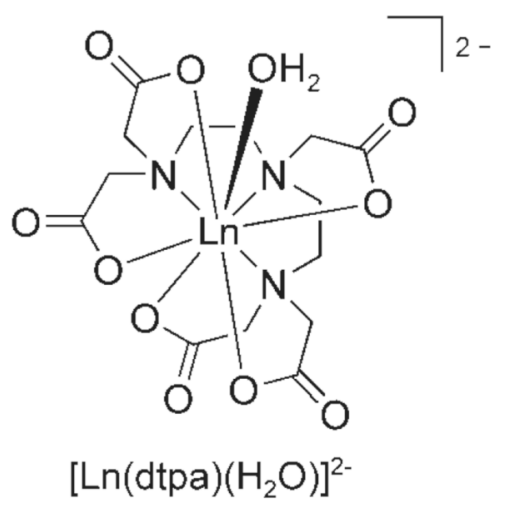

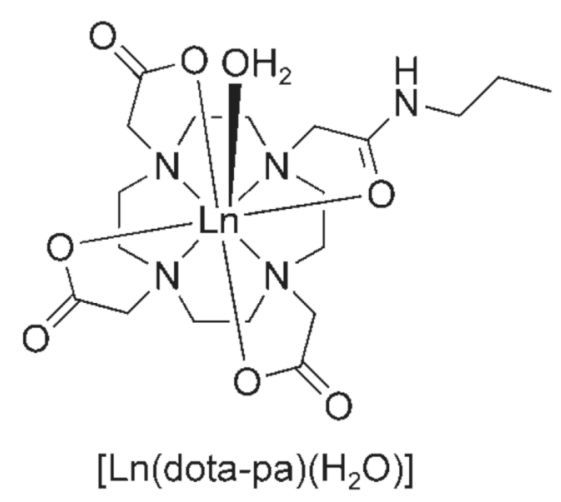

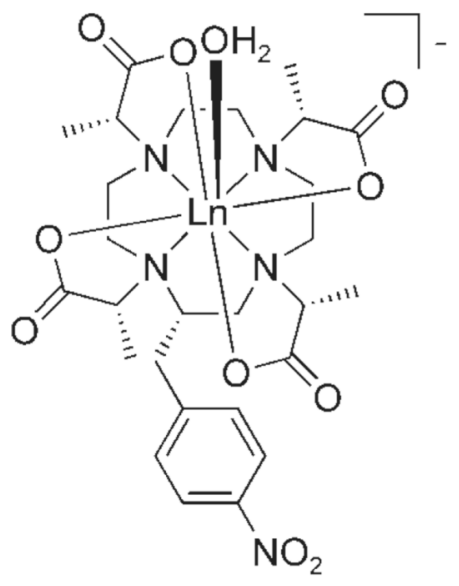

$\left[\mathrm{Ln}(\mathrm{S}-\mathrm{RRRR-1})\left(\mathrm{H}_{2} \mathrm{O}\right)\right]^{-}$

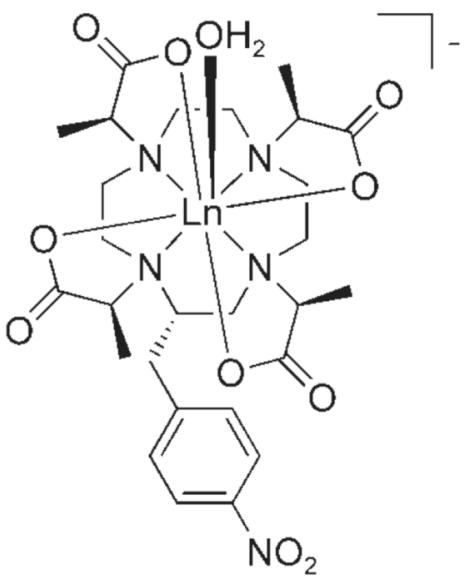

$\left[\mathrm{Ln}(\mathrm{S}-\mathrm{SSSS}-1)\left(\mathrm{H}_{2} \mathrm{O}\right)\right]^{-}$

\section{Results and Discussion}

The typical EPR spectrum of a $\mathrm{Gd}^{3+}$ complex is a single broad line, the shape of which can be analyzed to extract such parameters as: the magnitude of the static ZFS; the amplitude of the modulation around this average value, the so-called transient ZFS; and the correlation times for Brownian rotation and for the transient ZFS modulation. In order to reduce the number of parameters involved in analyzing the EPR spectra and improve the reliability of the values obtained the rotational correlation times of the complexes were measured independently. The method chosen for measuring the rotational correlation times was analysis of the Curie relaxation of the ligand protons of the corresponding terbium complexes as described by Aime 
et al.[23] and Dunand et al.[24] In the case of the complexes $\left[\mathrm{Tb}(S-S S S S-\mathbf{1})\left(\mathrm{D}_{2} \mathrm{O}\right)\right]^{-}$and $[\mathrm{Tb}$ $\left.(S-R R R R-1)\left(\mathrm{D}_{2} \mathrm{O}\right)\right]^{-}$this analysis is complicated by the loss of symmetry induced by the nitrobenzyl substituent. In the previously reported studies on the $C_{4}$ symmetric complexes of [Tb $($ dota $\left.)\left(\mathrm{H}_{2} \mathrm{O}\right)\right]^{-}$and $\left[\mathrm{Tb}-(\text { dotam })\left(\mathrm{H}_{2} \mathrm{O}\right)\right]^{3+}$ the ligand proton resonances are well resolved and readily assigned.[23,24] The ${ }^{1} \mathrm{H}$ NMR spectra of $\left.\mathrm{Tb}(S-S S S S-\mathbf{1})\left(\mathrm{D}_{2} \mathrm{O}\right)\right]^{-}$and $[\mathrm{Tb}(S-R R R R-\mathbf{1})$ $\left.\left(\mathrm{D}_{2} \mathrm{O}\right)\right]^{-}$(Figure 1) show overlapping resonances in some regions but a total of 11 of the 15 macrocyclic ring protons, four axial and all seven equatorial protons, can be identified.

Despite the presence of overlapping peaks that made measurement of peak integral difficult, good inversion recovery profiles of these 11 resonances were obtained at 200, 400 and 500 $\mathrm{MHz}$ and 295 and $333 \mathrm{~K}$. Longitudinal proton relaxation times in the millisecond range were determined from these data. A clear acceleration in the relaxation rate was observed with increasing magnetic field. In the absence of crystallographic data on the complexes of $[\mathrm{Tb}(\mathbf{1})$ $\left.\left(\mathrm{H}_{2} \mathrm{O}\right)\right]^{-}$the same $\mathrm{Tb}-\mathrm{H}$ distances reported for $\left[\mathrm{Tb}(\text { dota })\left(\mathrm{H}_{2} \mathrm{O}\right)\right]^{-}$by Aime et al.[23] were used to perform a Curie relaxation analysis. The nitrobenzyl substituent is thought to induce slight distortions into the conformation of the ethylene bridge on which it is located[27] which may have a small effect on those $\mathrm{Tb}-\mathrm{H}$ distances. It was not anticipated that the structure of the other ethylene bridges of the macrocyclic ring would be altered in any way by the presence of the nitrobenzyl substituent. On this basis one can assume that the $\mathrm{Tb}-\mathrm{H}$ distances in $[\mathrm{Tb}(\mathbf{1})$ $\left.\left(\mathrm{D}_{2} \mathrm{O}\right)\right]^{-}$and $\left[\mathrm{Tb}(\operatorname{dota})\left(\mathrm{H}_{2} \mathrm{O}\right)\right]^{-}$should be very close. For both complexes, the rotational correlation time at $298 \mathrm{~K}$ was determined for each recorded temperature. The values determined were very similar and afforded an average correlation time $\tau_{R}^{298}\left(D_{2} \mathrm{O}\right)=120.1 \mathrm{ps}$ (Supporting Information). Use of this average $\tau_{\mathrm{R}}^{298}$ value did not, on average, increase the mean error in the predicted relaxation rates, $\left\langle\Delta\left(1 / T_{1}\right)\right\rangle$, by more than $30 \mathrm{~s}^{-1}$, compared to the total experimental relaxation rates of 300-3000 s$~ s^{-1}$ (see Supporting Information), indicating that this average $\tau_{\mathrm{R}}^{298}$ value could reasonably be used in further calculations.

Continuous wave EPR spectra of $\left[\mathrm{Gd}(S-S S S S-\mathbf{1})\left(\mathrm{H}_{2} \mathrm{O}\right)\right]^{-}$and $\left[\mathrm{Gd}(S-R R R R-\mathbf{1})\left(\mathrm{H}_{2} \mathrm{O}\right)\right]^{-}$were recorded at X-band $(9.08 \mathrm{GHz})$ and $\mathrm{W}$-band $(94.2 \mathrm{GHz})$ at temperatures between 0 and $70^{\circ} \mathrm{C}$. The W-band spectra were approximately Lorentzian in shape. The peak-to-peak widths, $\Delta H_{\mathrm{pp}}$, central fields, $B_{0}$, and hyperfine coupling constants, $A$, were extracted by fitting a superposition of Lorentzians to each experimental spectrum with automatic phase and baseline adjustment. Because the $\mathrm{W}$-band spectra were relatively sharp the data treatment required that the minor gadolinium isotopes, ${ }^{155} \mathrm{Gd}\left(14.8 \%, \mathrm{I}={ }^{3} / 2, \gamma=-0.8273 \times 10^{7} \mathrm{~s}^{-1} \mathrm{~T}^{-1}\right)$ and ${ }^{157} \mathrm{Gd}$ $\left(15.65 \%, \mathrm{I}={ }^{3} / 2, \gamma=-1.0792 \times 10^{7} \mathrm{~s}^{-1} \mathrm{~T}^{-1}\right)$, be taken into account. Previous studies have shown that hyperfine coupling constants of $\mathrm{A}_{155_{\mathrm{Gd}}}=5.67 \mathrm{G}$ and $\mathrm{A}_{157 \mathrm{Gd}}=4.34 \mathrm{G}$ can be reasonably be assumed for these isotopes.[22] When these $A$ values were used to extract real $\Delta H_{\mathrm{pp}}$ values from the W-band spectra, values that were 1.0-1.5 G lower than the apparent line width of 10$20 \mathrm{G}$ were obtained. The X-band spectra deviated significantly from an ideal Lorentzian lineshape, especially in the low-field region of the spectrum, where the spectra frequently display a "hump" $\approx 300 \mathrm{G}$ below the central field, an example of which is shown (Figure 2).

Reproduction of the X-band line-shapes was improved by applying a phase-correction; this allowed the lines to be reasonably reproduced with a Lorentzian fit $( \pm 10 \%)$. A similar absolute accuracy $(20-30 \mathrm{G})$ can be estimated for the central field. $\Delta H_{\mathrm{pp}}$ values between $200-300 \mathrm{G}$ at $\mathrm{X}$-band (cf. $\approx 100 \mathrm{G}$ for $\left[\mathrm{Gd}(\operatorname{dota})\left(\mathrm{H}_{2} \mathrm{O}\right)\right]^{-}$and $400-600 \mathrm{G}$ for $\left[\mathrm{Gd}(\mathrm{dtpa})\left(\mathrm{H}_{2} \mathrm{O}\right)\right]^{2-}$ and $[\mathrm{Gd}(\mathrm{dtpa}-$ bma)-( $\left.\left.\left.\mathrm{H}_{2} \mathrm{O}\right)\right]\right)[28]$ indicate that electron-spin relaxation is relatively slow in both $[\mathrm{Gd}(\mathbf{1})$ $\left.\left(\mathrm{H}_{2} \mathrm{O}\right)\right]^{-}$complexes. 
The W- and X-band EPR data were then analyzed within the framework of the Rast model of 2nd order static and transient ZFS relaxation[19,29,30] using only the reduced $\Delta H_{\mathrm{pp}}$ and $B_{0}$ values rather than the full line shape, width and shifts. The model assumes that the electron spin relaxation is determined by the, so-called, static or average ZFS, which is rapidly modulated by molecular tumbling, and by the transient ZFS, which is modulated by random distortions within the complex. The static and transient ZFS were limited to 2nd order terms, although 4 th and 6th order terms are also possible for spin $\mathrm{S}={ }^{7} / 2^{\text {systems, }}$ such as $\mathrm{Gd}^{3+}$. The value of $\tau_{\mathrm{R}}^{298}$ used in the analysis was fixed to the value determined in $\mathrm{D}_{2} \mathrm{O}$ from the Curie relaxation study divided by the ratio of the viscosities of $\mathrm{D}_{2} \mathrm{O}$ and $\mathrm{H}_{2} \mathrm{O} ; \eta^{298}\left(\mathrm{D}_{2} \mathrm{O}\right) / \eta^{298}$ $\left(\mathrm{H}_{2} \mathrm{O}\right)=1.22$. The activation energy for rotation was fixed to $E_{\mathrm{R}}=18 \mathrm{kJmol}^{-1}$ for both complexes (consistent with the temperature dependence of $\mathrm{H}_{2} \mathrm{O}$ viscosity). The final value obtained, $\tau_{\mathrm{R}}^{298}\left(\mathrm{H}_{2} \mathrm{O}\right)=98.4 \mathrm{ps}$, is at the high end of acceptable values for DOTA-type complexes $\left(\tau_{\mathrm{R}}^{298}=80-100 \mathrm{ps}\right),[19]$ however, this result is expected when one considers the increase hydrodynamic volume that must occur upon introduction of the nitrobenzyl substituent. The absence of very high frequency EPR data meant that the natural $g$ factor could not be accurately determined; nonetheless, using a value of 1.9917 afforded good agreement between the theoretical central fields and the experimental W-band values. The EPR data were fitted to the Rast model using a least squares procedure (Figure 3, the central field is shown as the apparent $g$ factor, $\left.g^{\text {app }}=h v /\left(\mu_{\mathrm{B}} B_{0}\right)\right)$. The parameters obtained from this fitting procedure: the static ZFS magnitude parameter $\left(a_{2}\right)$, the rotational correlation time at room temperature $\left(\tau_{\mathrm{R}}^{298}=1 /\left(6 D_{\mathrm{R}}^{298}\right)\right)$ and its activation energy $\left(E_{\mathrm{R}}\right)$, the transient ZFS magnitude $\left(a_{2 \mathrm{~T}}\right)$, its associated correlation time $\left(\tau_{\mathrm{v}}^{298}\right)$ and activation energy $E_{\mathrm{v}}$; are collected in Table 1 . The fitted and experimental peak-to-peak widths at both fields are in good agreement and, although the apparent $g$ factors also fit well at W-band, the agreement is less good at X-band. The estimated error in the central field measurement—about $20 \mathrm{G}$ and equivalent to $\Delta g \approx 0.013$ — can only partially explain this discrepancy in the apparent $g$ factor at X-band. The theoretical approach taken in this study is based on Redfield's theory[31] which assumes that the spin Hamiltonian is modulated by perturbation that are small, and/or have short correlation times (in general, | $H_{1} \mid \tau \ll 1$, where $H_{1}$ is a time-dependent perturbing Hamiltonian, in our case the ZFS, and $\tau$ the correlation time for its modulation).[32] The non-Lorentzian line-shape of the spectra recorded at X-band suggests that this system may not completely conform to Redfield's theory at these EPR frequencies. Rigorous Monte-Carlo simulations[33] of $\left[\mathrm{Gd}(\operatorname{dota})\left(\mathrm{H}_{2} \mathrm{O}\right)\right]^{-}$have shown that, even at low temperature, the $\mathrm{X}$-band line width could adequately be predicted by Red-field Qs approximations. However, the dynamic frequency shifts[34] responsible for the temperature and EPR frequency dependence of the apparent $g$ factor have not been studied using that general method. Another exact approach, perhaps more suitable for the simulation of continuous-wave spectra but involving time-consuming simulations that make it unpractical for experimental data fitting, uses the stochastic Liouville equation.[35,36] Using such a method, it may prove to be the case that these shifts are more sensitive to violations of Redfield's approximations than the peak-to-peak widths. Furthermore, as our approach assumes isotropic rotation the presence of the nitrobenzyl substituent in the $\left[\mathrm{Gd}(\mathbf{1})\left(\mathrm{H}_{2} \mathrm{O}\right)\right]^{-}$ complexes may well induce anisotropic rotation in these complexes which could be the cause of the non-Lorentzian EPR lines and the deviation of the apparent $g$ factors from the theoretical predictions. Isotropic rotation is not a requirement of Redfield's approximation and a computationally inexpensive theoretical treatment of anisotropic motion in $S>1 / 2$ systems could be performed by adding a second rotation correlation time and an angle between the rotation and ZFS axes as new parameters. Such a model, combined with an extensive experimental EPR study of a system with known anisotropy, would be a valuable addition to the researchers' toolset and would allow an unambiguous answer to that particular question. 
Since the EPR line-widths measured for $\left[\mathrm{Gd}(S-R R R R-\mathbf{1})\left(\mathrm{H}_{2} \mathrm{O}\right)\right]^{-}$and $\left[\mathrm{Gd}(S-S S S S-\mathbf{1})\left(\mathrm{H}_{2} \mathrm{O}\right)\right]^{-}$ are comparable it is not altogether surprising that the magnitude of the static $\operatorname{ZFS}\left(a_{2}\right)$, the magnitude of the transient ZFS $\left(a_{2 \mathrm{~T}}\right)$ and the correlation time $\left(\tau_{\mathrm{v}}^{298}\right)$ of each complex are similar. Furthermore, the zero-field splitting parameters obtained for both $\left[\mathrm{Gd}(\mathbf{1})\left(\mathrm{H}_{2} \mathrm{O}\right)\right]^{-}$complexes closely resemble those obtained from extensive EPR studies of $\left[\mathrm{Gd}(\text { dota })\left(\mathrm{H}_{2} \mathrm{O}\right)\right]^{-}$.[19] The similarity of the ZFS parameters in these three complexes suggests that the ZFS is not significantly affected by the changes in ligand field induced by changing a SAP isomer into a TSAP isomer, consistent with the almost identical electron spin relaxation parameters derived for the two isomers from fitting of NMRD data.[16] The differences between the SAP and TSAP coordination geometries are relatively small: there is a change in the twist angle between the $\mathrm{N}_{4}$ and $\mathrm{O}_{4}$ coordination planes from about 45 to about $29^{\circ}$, and there is also a slight increase in the $\mathrm{Ln}-\mathrm{OH}_{2}$ bond length. Nonetheless, these differences are large enough that they can induce significant differences in some properties that are related to ligand field. For example, a significant difference is observed between the hyperfine shifts of the ligand protons in the SAP isomer (S-RRRR) and the TSAP isomer (S-SSSS) (Figure 1). $[8,14,16,38]$ This is the result of differences in the pseudo-contact shift contribution to the overall shift, differences that are related directly to changes in ligand field.[26] The differences in ligand field between the two coordination isomers have also been found to have a significant effect on the Cotton bands in ytterbium complexes.[26] Thus the SAP and TSAP coordination geometries induce different ligand fields into the $\mathrm{Ln}^{3+}$ ion, which may be expected to produce different ZFSs in the $\mathrm{Gd}^{3+}$ complexes; however, EPR measurements show that the magnitude of the parameter $\mathrm{a}_{2}$ is essentially the same for both isomers. In $C_{4}$-symmetric complexes the axial component of the ZFS spherical tensor must lie along the main rotation axis and so both complexes would be expected to have the same ZFS orientation. However, slight distortions in the coordination geometry that lower the symmetry of the metal ion may give rise to a rhombic term that may not have the same orientation in each complex. It may be that the ligand fields of the SAP and TSAP isomers result in differences in the orientation of this perpendicular component but do not affect the magnitude of the ZFS.

\section{Luminescence studies}

Ligand-field effects are normally studied through photophysical measurements of the metal ion, either absorption or emission. For lanthanide ions the amount of information that can be obtained from these studies is limited by shielding of the $4 \mathrm{f}$ orbitals by the $5 \mathrm{~d}$ orbitals. As a result of this shielding the effect of the ligand field is small relative to the spin-orbital coupling $\left(\approx 100 \mathrm{~cm}^{-1}\right.$ versus $\left.\approx 2000 \mathrm{~cm}^{-1}\right)$. In consequence, the emission spectra of lanthanide ions are characterized by sharp emission bands that correspond to the Russell-Saunders (spin-orbit coupling) states of the ground state. Information about the ligand field is contained within these sharp emission bands and can therefore only be clearly discerned at higher spectral resolutions. Under Laporte selection rules $\mathrm{f}-\mathrm{f}$ transitions are forbidden: nevertheless, some transitions are permitted under electric or magnetic dipole selection rules through the mixing of $5 \mathrm{~d}$ and $4 \mathrm{f}$ orbitals that arises from distortions of the coordination sphere by vibrational motion. In consequence the intensities of $\mathrm{f}-\mathrm{f}$ transitions remain low. The $\mathrm{Eu}^{3+}$ ion is an attractive candidate for studying transitions of the $4 \mathrm{f}$ electrons because the emissive ${ }^{5} \mathrm{D}_{0}$ state, being nondegenerate, is not split by the ligand field. This means that transitions from ${ }^{5} \mathrm{D}_{0}$ to the ${ }^{7} \mathrm{~F}_{\mathrm{J}}$ manifold exhibit ligand-field patterns arising solely from the degeneracy of the $\mathbf{J}$ state of the ${ }^{7} \mathrm{~F}$ ground state.

Emission spectra of the $\mathrm{Eu}^{3+}$ complexes of $S$-RRRR-1, S-SSSS-1, DOTA and DTPA were recorded in aqueous solution at $298 \mathrm{~K}$ and $0.05 \mathrm{~nm}$ resolution (Figure 4). The most noticeable aspect of these spectra is the strong similarities between the spectra of the three macrocyclic complexes. The relative intensity of each band is similar for each complex, which suggests comparable $5 \mathrm{~d} / 4 \mathrm{f}$ orbital mixing in each case. There are, however, some noticeable differences 
in the ligand fields of the SAP and TSAP coordination geometries. The ${ }^{7} \mathrm{~F}_{0}$ state of $\mathrm{Eu}^{3+}$ is also non-degenerate and so a single line is observed for the ${ }^{5} \mathrm{D}_{0} \rightarrow{ }^{7} \mathrm{~F}_{0}$ band at about $578 \mathrm{~nm}$. The symmetry of the inner coordination sphere of the $\mathrm{Eu}^{3+}$ ion in DOTA-type complexes is $C_{4}$ and so two ${ }^{5} \mathrm{D}_{0} \rightarrow{ }^{7} \mathrm{~F}_{1}$ transitions centred around $591 \mathrm{~nm}$ are possible. The ligand field induced by the SAP coordination geometry induces a large separation between these two transitions $\left(219 \mathrm{~cm}^{-1}\right)$ whereas the separation in the TSAP isomer is very small $\left(58 \mathrm{~cm}^{-1}\right)$. The difference in ligand-field splitting between the two isomers is large enough that both isomers may be identified in the $\Delta \mathrm{J}=1$ band of the $\left[\mathrm{Eu}(\operatorname{dota})\left(\mathrm{H}_{2} \mathrm{O}\right)\right]^{-}$spectrum. Complexes with $C_{4}$ symmetry may have 4 transitions in the ${ }^{5} \mathrm{D}_{0} \rightarrow{ }^{7} \mathrm{~F}_{2}$ band $(615 \mathrm{~nm})$, with one apparent exception these transitions lie at approximately the same energy levels in the SAP isomer. In contrast the ligand field of the TSAP isomer causes these transitions to appear at different energies and four distinct transitions can be observed. Significantly the $\Delta J=2$ band is "hypersensitive" a phenomenon, the origins of which are not clearly understood, that leads to significant fluctuations in the intensity of this band. The intensities of this band in all three macrocyclic complexes are largely unchanged by the changes in ligand field induced by isomerization. The ${ }^{5} \mathrm{D}_{0} \rightarrow{ }^{7} \mathrm{~F}_{3}$ band $(650 \mathrm{~nm})$ is weak but may be split into five transitions in $\mathrm{C}_{4}$ symmetric complexes. Owing to the weakness of this band it is difficult to identify these transitions and the only noticeable difference between the two coordination geometries is an increase in the intensity of the transition at lowest energy, an observation also reflected in the spectrum of [Eu (dota) $\left.\left(\mathrm{H}_{2} \mathrm{O}\right)\right]^{-}$. The ${ }^{5} \mathrm{D}_{0} \rightarrow{ }^{7} \mathrm{~F}_{4}$ band (centred at $694 \mathrm{~nm}$ ) also exhibits significant differences depending upon the coordination geometry. $C_{4}$ symmetry results in seven possible transitions of which two are observed to be more intense than the others in both SAP and TSAP isomers. These transitions are well separated in the spectrum of the TSAP isomer, with five clearly identifiable peaks and a further two small peaks hidden by the more intense peaks. In the case of the SAP isomer only four peaks may be clearly discerned since the peaks are less well separated and greater peak overlap is observed. Comparison of the emission spectra of the SAP and TSAP isomers with that of DOTA reveal that peaks arising from the SAP and TSAP isomeric forms of DOTA can also be identified in the $\Delta \mathrm{J}=4$ band.

The emission spectra of $\left[\mathrm{Eu}(S-R R R R-\mathbf{1})\left(\mathrm{H}_{2} \mathrm{O}\right)\right]^{-}$and $\left[\mathrm{Eu}(S-S S S S-\mathbf{1})\left(\mathrm{H}_{2} \mathrm{O}\right)\right]^{-}$were fitted to Gaussian-Lorentzian lines using commercially available peak fitting software (PeakFit v4.12, Systat Software, 2007) to afford the relative energies of the each transition in the spectrum, except those of the $\Delta \mathrm{J}=3$ band which was too weak to allow suitable fitting. The resulting energy level diagram, including ligand-field splitting, is shown in Figure 5. In principle the information contained in this diagram, along with the relative intensities of each peak, can be used to calculate the ligand-field parameters: $A_{0}{ }^{0}, A_{2}{ }^{0}$, etc. of the $\mathrm{Eu}^{3+}$ ion in each coordination geometry. However, although a number of approaches are available for this type of calculation $[39,40]$ they are extremely complex, having to account for all inter-electronic interactions and relativistic effects. Despite some sophisticated models, it remains difficult to be certain that calculations performed on a single system have yielded reliable ligand-field parameters. Furthermore, the ligand-field parameters obtained for $\mathrm{Eu}^{3+}$ cannot be directly applied to $\mathrm{Gd}^{3+}$, nor used to predict the $\mathrm{Gd}^{3+}$ values, to afford a model of the ZFS. So while we await advances in the quantum mechanical treatment of lanthanide ligand-field theory, a qualitative assessment of the effects of the ligand field upon the ZFS is the best that can currently be put forward. Differences between the ligand fields of the SAP and TSAP isomers are evident from their emission spectra. Furthermore, it has been shown that differences in the separation of the two transitions of the $\Delta \mathrm{J}=1$ band arise from a change in the axial ligand-field parameter $A_{2}{ }^{0}$. [41] Despite this, and possibly other, changes in the ligand field only small variations in the ZFS of gadolinium are observed for the SAP and TSAP isomers of DOTA-type complexes.

The electron-spin relaxation parameters of $\left[\mathrm{Gd}(\mathrm{dtpa})\left(\mathrm{H}_{2} \mathrm{O}\right)\right]^{2-}$ are very different from those of $\left[\mathrm{Gd}(\operatorname{dota})\left(\mathrm{H}_{2} \mathrm{O}\right)\right]^{-}$and the DOTA-type complexes studied here (Table 1). However, the magnitude of the transient ZFS $\left(a_{2 \mathrm{~T}}\right)$ of $\left[\mathrm{Gd}(\mathrm{dtpa})\left(\mathrm{H}_{2} \mathrm{O}\right)\right]^{2-}$ is very similar to that found for 
the DOTA-type complexes so it would appear that the magnitude of the static ZFS is the primary source of the difference in electron-spin relaxation. The electron spin relaxation time of $\left[\mathrm{Gd}(\mathrm{dtpa})\left(\mathrm{H}_{2} \mathrm{O}\right)\right]^{2-}$ is much shorter because the static ZFS is almost twice the magnitude of that of $\left[\mathrm{Gd}(\mathrm{dota})\left(\mathrm{H}_{2} \mathrm{O}\right)\right]^{-}$suggesting that a very different ligand field is present. It is hardly surprising therefore that overall form of the emission spectrum of $\left[\mathrm{Eu}(\mathrm{dtpa})\left(\mathrm{H}_{2} \mathrm{O}\right)\right]^{2-}$ is substantially different from any of those recorded for the DOTA-type complexes. Most notably the ${ }^{5} \mathrm{D}_{0} \rightarrow{ }^{7} \mathrm{~F}_{2}$ band is considerably more intense whereas the ${ }^{5} \mathrm{D}_{0} \rightarrow{ }^{7} \mathrm{~F}_{4}$ band is less intense. The latter effect is most probably the result of variations in the extent of $5 \mathrm{~d} / 4 \mathrm{f}$ orbital mixing, notably both $\mathrm{d} / \mathrm{f}$ orbital mixing and modulation of the ZFS are the result of distortions of the ligand field through vibrational motion. The change in intensity of the $\Delta \mathrm{J}=2$ band is most probably a hyper-sensitivity effect and so the origins of this change are, as yet, unknown. It is impossible to tell if, or how, the phenomenon of hypersensitivity is related to the magnitude, or modulation, of the ZFS. However, the results presented herein indicate that a relationship between the two cannot, at present, be ruled out. The symmetry of the inner coordination sphere of $\mathrm{Eu}^{3+}$ in DTPA is $C_{S}$, lower than that of DOTA-type complexes, and this leads to an increase in the number of non-degnerate energy levels, 25 versus 19 in $C_{4}$ symmetric complexes. The number of levels in the ${ }^{8} \mathrm{~S}$ state of $\mathrm{Gd}^{3+}$ is unaffected by this change in symmetry and so in the absence of an external magnetic field four Kramers doublets will be present for the $\mathrm{J}={ }^{7} / 2$ manifold (ground state) for all the complexes discussed herein. The change in symmetry could affect the orientation of the ZFS tensor, which is close to axial in the DOTA-type complexes but could lie in any direction in DTPA and may cause a larger ZFS and faster electron spin relaxation of $\left[\mathrm{Gd}(\mathrm{dtpa})\left(\mathrm{H}_{2} \mathrm{O}\right)\right]^{2-}$. In DOTA-type complexes, more subtle effects appear to be at play. As shown by luminescence, the ligand field is clearly affected be coordination geometry (SAP vs TSAP), however, according to our EPR and NMR results, the ZFS magnitude is not. Whether the ZFS tensor orientation in both isomers is different remains to be seen. The amount of information available here is limited and while it allows for the exclusion of some relationships between ligand-field effects and electron-spin relaxation it can only hint at the defining relationship.

\section{Conclusion}

Clearly more work will be required if the complete relationship between electronic relaxation and coordination environment is to be elucidated. Nonetheless, the work presented herein suggests that relatively small changes in the ligand field have only marginal effects upon the magnitude of the ZFS despite significant changes in the ligand field. The result is that the electron-spin relaxation parameters for the SAP and TSAP coordination geometries are very similar. This similarity suggests that is will not be possible to distinguish the two coordination geometries by EPR at any field strength. Furthermore, the similarity between the electron spin relaxation parameters of each isomer and those obtained for $\left[\mathrm{Gd}(\right.$ dota $)\left(\mathrm{H}_{2} \mathrm{O}\right)^{-}$suggests that modulation of the ZFS is not affected by interchange of the coordination geometry, which occurs at a much slower rate than electron spin relaxation. The transient ZFS must be modulated by much faster processes, such as vibration and rotation. The limited amount of information available in this study is unable to point us in the direction of a direct relationship between ligand field (and thus ligand structure) and electron spin relaxation. Further studies examining the effects of ligand charge and different donor atoms may provide more insight into this apparently complex relationship.

\section{Experimental Section}

\section{NMR Studies}

Samples of $\mathrm{H}[\mathrm{Tb}(S-R R R R-\mathbf{1})(\mathrm{HSO})], \mathrm{H}\left[\mathrm{Tb}(S-S S S S-\mathbf{1})\left(\mathrm{H}_{2} \mathrm{O}\right)\right], \mathrm{H}\left[\mathrm{Gd}(S-R R R R-\mathbf{1})\left(\mathrm{H}_{2} \mathrm{O}\right)\right], \mathrm{H}[\mathrm{Gd}$ $\left.(S-S S S S-\mathbf{1})\left(\mathrm{H}_{2} \mathrm{O}\right)\right], \mathrm{H}\left[\mathrm{Eu}(S-R R R R-\mathbf{1})\left(\mathrm{H}_{2} \mathrm{O}\right)\right]$ and $\mathrm{H}\left[\mathrm{Eu}(S-S S S S-\mathbf{1})\left(\mathrm{H}_{2} \mathrm{O}\right)\right]$ were prepared as 
previously described.[16] ${ }^{1} \mathrm{H}$ NMR experiments on the two terbium(III) complexes were performed on Bruker AVANCE-500, DPX-400 and AVANCE-200 spectrometers operating at 500, 400 and $200 \mathrm{MHz}$, respectively. The sample temperature during these experiments was controlled using a Bruker BVT-3000 temperature control unit and accurately measured using the standard substitution technique.[42] Each experiment was performed at both 295.2 and $332.7 \mathrm{~K}$. Samples were prepared by dissolving each terbium(iii) complex in $\mathrm{D}_{2} \mathrm{O}$ to afford a solution of $\left[\mathrm{Tb}(S-S S S S-\mathbf{1})\left(\mathrm{D}_{2} \mathrm{O}\right)\right]^{-}$at $9 \mathrm{mmolkg}^{-1}$ and of $\left[\mathrm{Tb}(S-R R R R-\mathbf{1})\left(\mathrm{D}_{2} \mathrm{O}\right)\right]^{-}$at 13 mmolkg-1 ${ }^{-1}$. The protons of the macrocycle in each complex were assigned according to the assessment of chemical shifts by EXSY and COSY experiments on the corresponding ytterbium complexes.[26] The longitudinal relaxation times $\left(T_{1}\right)$ of these protons were determined using the inversion recovery pulse sequence[43] and the data fitted using the XWINNMR programme for Bruker spectrometers. A simultaneous analysis of all longitudinal relaxation rates obtained for a single complex at a given temperature was performed with the VISUALISEUR/OPTIMISEUR[44] programme according to the procedure described by Dunand et al.[24] For the purposes of data treatment it was assumed the system obeyed Arrhenius Law and a value of $E_{\mathrm{R}}=16.5 \mathrm{kJmol}^{-1}$ was used, consistent with the temperature dependence of $\mathrm{D}_{2} \mathrm{O}$ viscosity.[45,46] This treatment afforded the rotational correlation time in $\mathrm{D}_{2} \mathrm{O}$ at $298 \mathrm{~K}\left(\tau_{\mathrm{R}}^{298}\left(\mathrm{D}_{2} \mathrm{O}\right)\right)$ as well as the non-Curie (i.e., essentially field-independent) relaxation rate for each proton.

\section{EPR Studies}

Continuous wave EPR spectra were recorded on $1 \mathrm{~mm}$ solutions of $\left[\mathrm{Gd}(S-R R R R-\mathbf{1})\left(\mathrm{H}_{2} \mathrm{O}\right)\right]^{-}$ and $\left[\mathrm{Gd}(S-S S S S-1)\left(\mathrm{H}_{2} \mathrm{O}\right)\right]^{-}$at around $9.08 \mathrm{GHz}$ (X-band) and about $94.2 \mathrm{GHz}$ (W-band) at temperatures between 273 and $343 \mathrm{~K}$. The spectrometer used for X-band measurements was a Varian E-112 and the magnetic field calibration was performed using a Varian E-500 Gaussmeter. The spectrometer used for W-band measurements was a custom-built instrument and the signal of $\mathrm{Mn}^{2+}$ in a plasticine sample[47] was used as a reference for the field calibration. The frequency was measured by a digital divider/counter. The temperature was adjusted using standard VT controllers and accurately measured with a copper-constantan thermocouple. Spectra were analyzed using the NMRICMA programme.[48]

\section{Luminescence studies}

Emission spectra were acquired in on Edinburgh Instruments FL900 fluorimeter exciting to the ${ }^{5} \mathrm{~L}_{6}$ state at $396 \mathrm{~nm}$. The spectra of $\left[\mathrm{Eu}(\mathrm{dtpa})\left(\mathrm{H}_{2} \mathrm{O}\right)\right]^{2-}$ and $\left[\mathrm{Eu}(\operatorname{dota})\left(\mathrm{H}_{2} \mathrm{O}\right)\right]^{-}$were acquired under steady state conditions. The spectra of $\left[\mathrm{Eu}(\mathbf{1})\left(\mathrm{H}_{2} \mathrm{O}\right)\right]^{-}$were acquired with a time gate of $200 \mathrm{~ms}$ and a time delay of $20 \mu \mathrm{s}$.

\section{Acknowledgements}

The authors thank Dr. Mark J. Nilges (Urbana) and Martial Rey (Lausanne) for their assistance with the EPR and 500 $\mathrm{MHz}^{1} \mathrm{H}$ NMR measurements, respectively. Financial assistance from the Swiss National Science Foundation (A.B.); the EU COST Action D18 "Lanthanide Chemistry for Diagnosis and Therapy" (L.M.); the Hughes Undergraduate Research Fellows Program (J.F.B.); the National Institutes of Health (CA-91597 and RR-01811, R.B.C.), (EB-04285, M.W.), (CA-115531 and RR-02584, A.D.S.); the Petroleum Research Fund of the American Chemical Society; and the Robert A. Welch Foundation (AT-584) is gratefully acknowledged.

\section{References}

1. Bloembergen N. J. Chem. Phys 1957;27:572.

2. Bloembergen N, Morgan LO. J. Chem. Phys 1961;34:842.

3. Bloembergen N, Purcell EM, Pound RV. Phys. Rev 1948;73:679.

4. Solomon I. Phys. Rev 1955;99:559. 
5. Solomon I, Bloembergen N. J. Chem. Phys 1956;25:261.

6. Caravan P, Ellison JJ, McMurry TJ, Lauffer RB. Chem. Rev 1999;99:2293. [PubMed: 11749483]

7. Brucher, E.; Sherry, AD. Chemistry of Contrast Agents in Medical Magnetic Resonance Imaging. Toth, E.; Merbach, AE., editors. New York: Wiley; 2001. p. 243

8. Woods M, Kovacs Z, Zhang S, Sherry AD. Angew. Chem 2003;115:6069.Angew. Chem. Int. Ed. 2003, 42, 5889.

9. Woods, M.; Sherry, AD. Proc. 26th Ann. Intl. Conf. IEEE EMBS; 2004. p. 5254

10. Laus S, Ruloff R, Toth E, Merbach AE. Chem. Eur. J 2003;9:3555.

11. Geraldes CFGC, Brown RD III, Cacheris WP, Koenig SH, Sherry AD, Spiller M. Magn. Reson. Med 1989;9:94. [PubMed: 2540397]

12. Sherry AD, Brown RD III, Geraldes CFGC, Koenig SH, Kuan KT, Spiller M. Inorg. Chem 1989;28:620.

13. Hoeft S, Roth K. Chem. Ber 1993;126:869.

14. Woods M, Aime S, Botta M, Howard JAK, Moloney JM, Navet M, Parker D, Port M, Rousseaux O. J. Am. Chem. Soc 2000;122:9781.

15. Aime S, Botta M, Fasano M, Marques MPM, Geraldes CFGC, Pubanz D, Merbach AE. Inorg. Chem 1997;36:2059. [PubMed: 11669824]

16. Woods M, Botta M, Avedano S, Wang J, Sherry AD. Dalton Trans 2005:3829. [PubMed: 16311635]

17. Dunand FA, Aime S, Merbach AE. J. Am. Chem. Soc 2000;122:1506.

18. Aime S, Barge A, Bruce JI, Botta M, Howard JAK, Moloney JM, Parker D, de Sousa AS, Woods M. J. Am. Chem. Soc 1999;121:5762.

19. Rast S, Borel A, Helm L, Belorizky E, Fries PH, Merbach AE. J. Am. Chem. Soc 2001;123:2637. [PubMed: 11456933]

20. Benmelouka M, Borel A, Moriggi L, Helm L, Merbach AE. J. Phys. Chem. B 2007;111:832. [PubMed: 17249827]

21. Clarkson RB, Smirnov AI, Smirnova TI, Kang H, Belford RL, Earle K, Freed JH. Mol. Phys 1998;95:1325.

22. Borel A, Kang H, Gateau C, Mazzanti M, Clarkson RB, Belford RL. J. Phys. Chem. A 2006;110:12434. [PubMed: 17091946]

23. Aime S, Barbero L, Botta M, Ermondi G. J. Chem. Soc. Dalton Trans 1992:225.

24. Dunand FA, Borel A, Merbach AE. J. Am. Chem. Soc 2002;124:710. [PubMed: 11804502]

25. Vipond J, Woods M, Zhao P, Tircso G, Ren JM, Bott SG, Ogrin D, Kiefer GE, Kovacs Z, Sherry AD. Inorg. Chem 2007;46:2584. [PubMed: 17295475]

26. Di Bari L, Pescitelli G, Sherry AD, Woods M. Inorg. Chem 2005;44:8391. [PubMed: 16270977]

27. Woods M, Kovacs Z, Kiraly R, Brucher E, Zhang S, Sherry AD. Inorg. Chem 2004;43:2845. [PubMed: 15106971]

28. Powell DH, Ni Dhubhghaill OM, Pubanz D, Helm L, Lebedev YS, Schlaepfer W, Merbach AE. J. Am. Chem. Soc 1996;118:9333.

29. Rast S, Fries PH, Belorizky E. J. Chim. Phys 1999;96:1543.

30. Rast S, Fries PH, Belorizky E. J. Chem. Phys 2000;113:8724.

31. Redfield AG. Adv. Magn. Reson 1965;1:1.

32. Fries PH, Belorizky E. J. Chem. Phys 2007;126:204503/1. [PubMed: 17552774]

33. Rast S, Fries PH, Belorizky E, Borel A, Helm L, Merbach AE. J. Chem. Phys 2001;115:7554.

34. Poupko R, Baram A, Luz Z. Mol. Phys 1974;27:1345.

35. Aman K, Westlund PO. Phys. Chem. Chem. Phys 2007;9:691. [PubMed: 17268680]

36. Borel A, Clarkson RB, Belford RL. J. Chem. Phys 2007;126:054510/1. [PubMed: 17302488]

37. Dunand FA, Borel A, Helm L. Inorg. Chem. Commun 2002;5:811.

38. Howard JAK, Kenwright AM, Moloney JM, Parker D, Woods M, Port M, Navet M, Rousseau O. Chem. Commun 1998:1381.

39. Sastri, VS.; Bunzli, JC.; Perumareddi, JR.; Rao, VR.; Rayudu, GVS. Modern Aspects of Rare Earths and Their Complexes. Amsterdam: Elsevier; 2003. 
40. Newman, DJ.; Ng, B. Crystal Field Handbook. Cambridge: Cambridge University Press; 2000.

41. Dickins RS, Parker D, Bruce JI, Tozer DJ. Dalton Trans 2003:1264.

42. Ammann C, Meier P, Merbach AE. J. Magn. Reson 1982;46:319.

43. Vold RL, Waugh JS, Klein MP, Phelps DE. J. Chem. Phys 1968;48:3831.

44. Yerly F, Dunand FA, Toth E, Figueirinha A, Kovacs Z, Sherry AD, Geraldes CFGC, Merbach AE. Eur. J. Inorg. Chem 2000:1001.

45. Kestin J, Imaishi N, Nott SH, Nieuwoudt JC, Sengers JV. Physica A 1985;134:38.

46. Harris KR, Woolf LA. J. Chem. Eng. Data 2004;49:1064-1069.

47. Rahimi-Moghaddam P, Upadrashta Y, Nilges MA, Weil JA. Appl. Magn. Reson 2003;24:113.

48. Helm L, Borel A. ICMA, Lausanne (2.7 ed.). 2000 

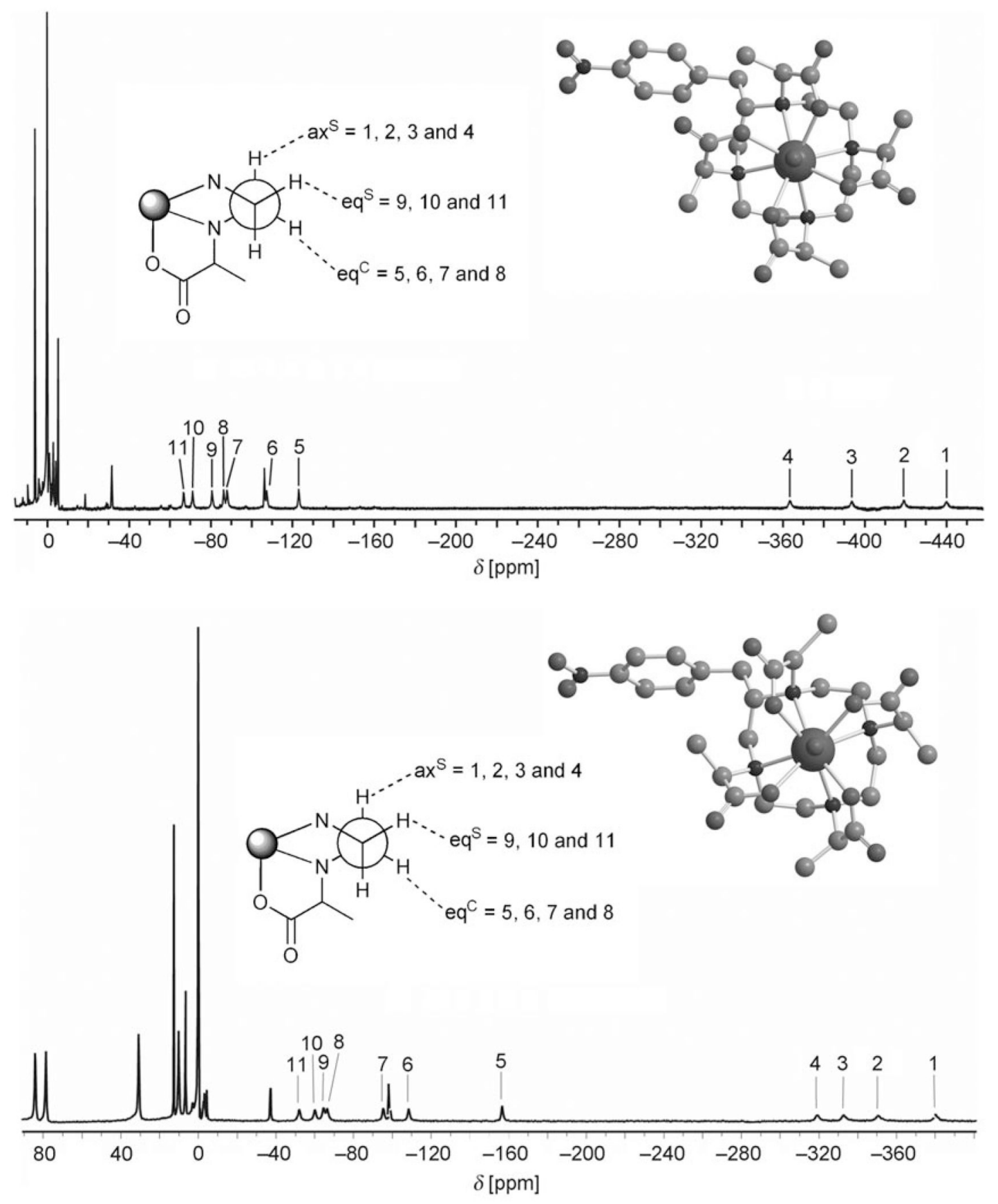

Figure 1.

The up-field region of the ${ }^{1} \mathrm{H}$ NMR spectra of $\left[\mathrm{Tb}(S-S S S S-1)\left(\mathrm{D}_{2} \mathrm{O}\right)\right]^{-}$recorded at $295.2 \mathrm{~K}$ in $\mathrm{D}_{2} \mathrm{O} 200 \mathrm{MHz}$ (bottom) and of $\left[\mathrm{Tb}(S-R R R R-1)\left(\mathrm{D}_{2} \mathrm{O}\right)\right]^{-}$recorded $332.7 \mathrm{~K}$ in $\mathrm{D}_{2} \mathrm{O}$ at $200 \mathrm{MHz}$ (top). The down-field regions of the spectra are not displayed owing to the limited bandwidth of the excitation pulse. The assignments of the protons of the macrocyclic ring are shown in which ax ${ }^{S}$ refers to the axial proton of the carbons located on the side of the ring and $\mathrm{eq}^{S}$, the equatorial proton of the same carbon. eq ${ }^{C}$ refers to the equatorial proton located on the carbon located on the corner of the ring.[25] Molecular models of the complexes are also shown, illustrating the difference in coordination geometry between two stereoisomers.[26] 


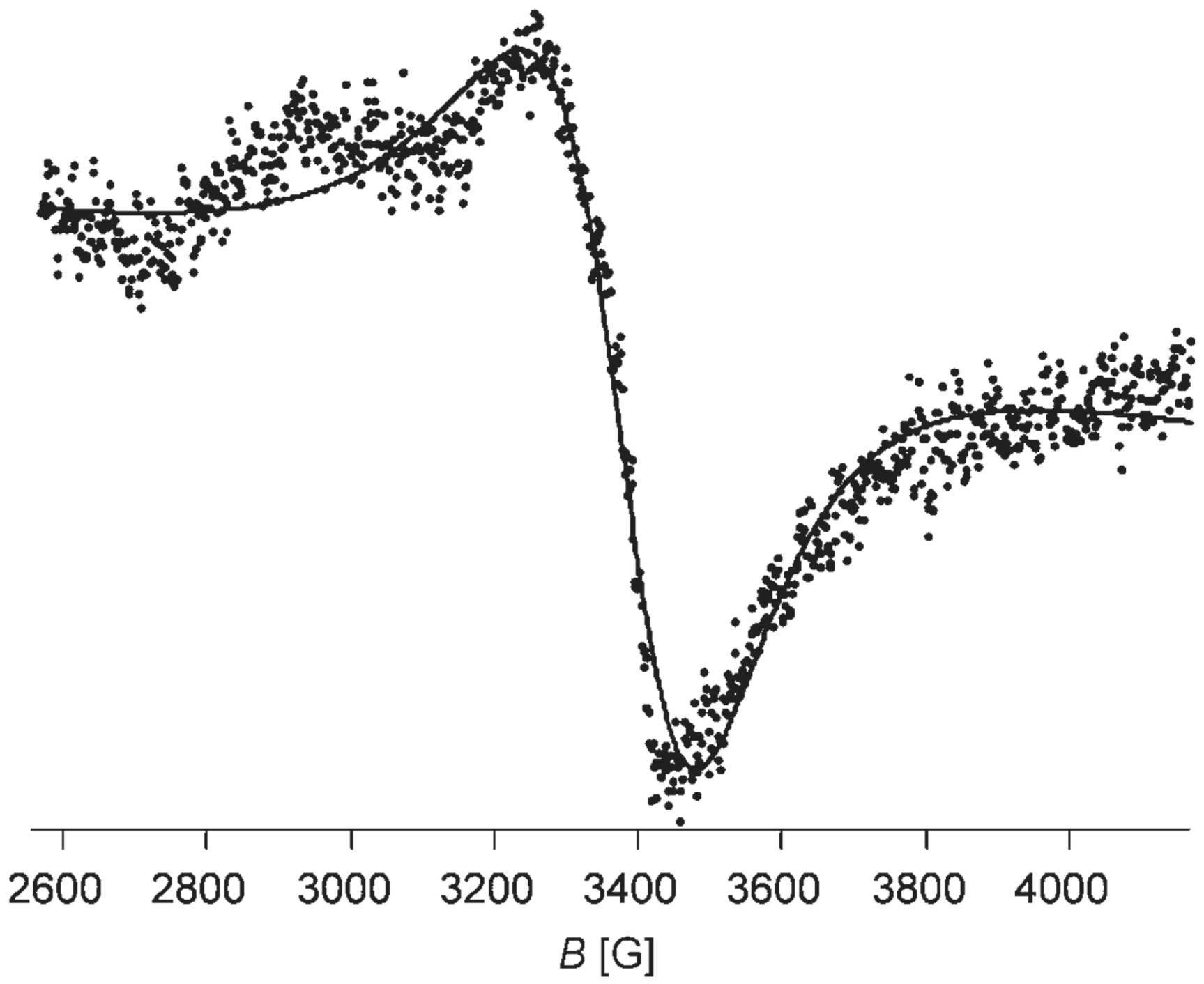

Figure 2.

A representative X-band EPR spectrum of $\left[\mathrm{Gd}(S-R R R R-\mathbf{1})\left(\mathrm{H}_{2} \mathrm{O}\right)\right]^{-}$. 

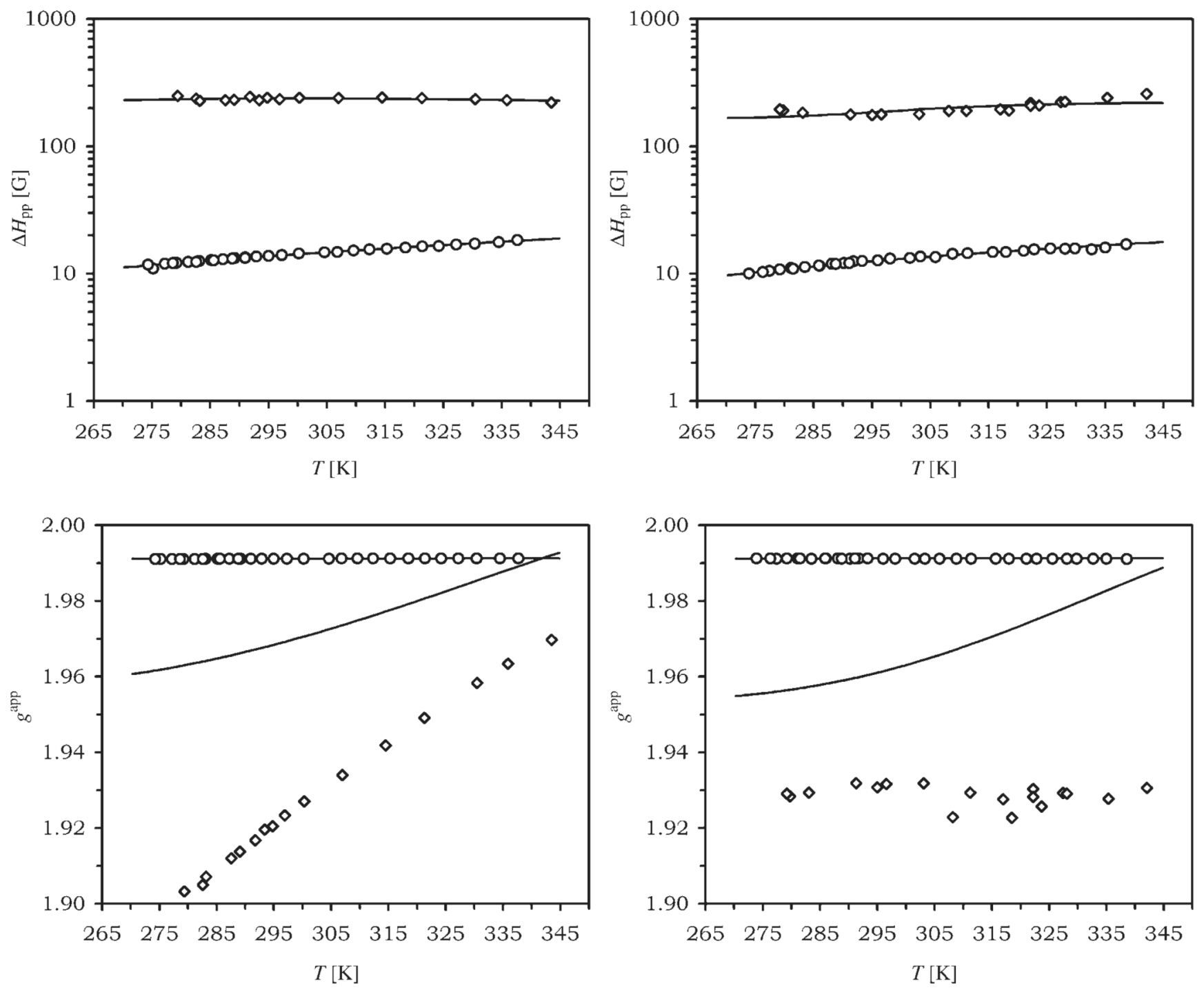

Figure 3.

Experimental and theoretical EPR peak-to-peak widths $\left(\Delta H_{\mathrm{pp}}\right)$ and apparent $g$ factors $\left(g^{\text {app }}\right)$, shown as a function of temperature, at $\mathrm{W}$-band $(\circ)$ and $\mathrm{X}$-band $(\diamond)$ for $[\mathrm{Gd}(S-R R R R-\mathbf{1})$

$\left.\left(\mathrm{H}_{2} \mathrm{O}\right)\right]^{-}$(left) and $\left[\mathrm{Gd}(S-S S S S-\mathbf{1})\left(\mathrm{H}_{2} \mathrm{O}\right)\right]^{-}$(right). 

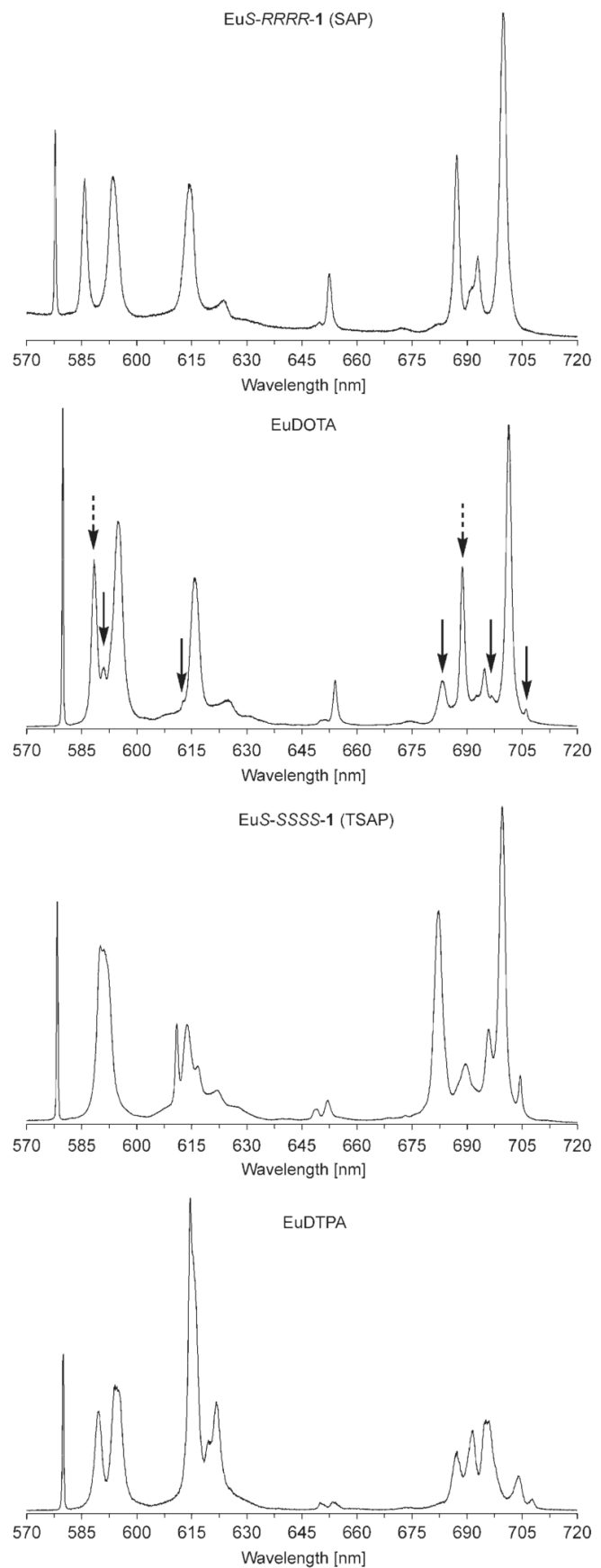

Figure 4.

Emission spectra of $\left[\mathrm{Eu}(S-R R R R-\mathbf{1})\left(\mathrm{H}_{2} \mathrm{O}\right)\right]^{-}$(top), $\left[\mathrm{Eu}(\mathrm{dota})\left(\mathrm{H}_{2} \mathrm{O}\right)\right]^{-}$(above, middle), $[\mathrm{Eu}(S-$ SSSS-1 $\left.)\left(\mathrm{H}_{2} \mathrm{O}\right)\right]^{-}$(below, middle) and $\left[\mathrm{Eu}(\mathrm{dtpa})\left(\mathrm{H}_{2} \mathrm{O}\right)\right]^{2-}$ (bottom). Peaks characteristic of one coordination isomer in the spectrum of $\left[\mathrm{Eu}(\operatorname{dota})\left(\mathrm{H}_{2} \mathrm{O}\right)\right]^{-}$are indicated with arrows; dashed arrows indicate the SAP isomer, whereas solid arrows indicate the TSAP isomer. 


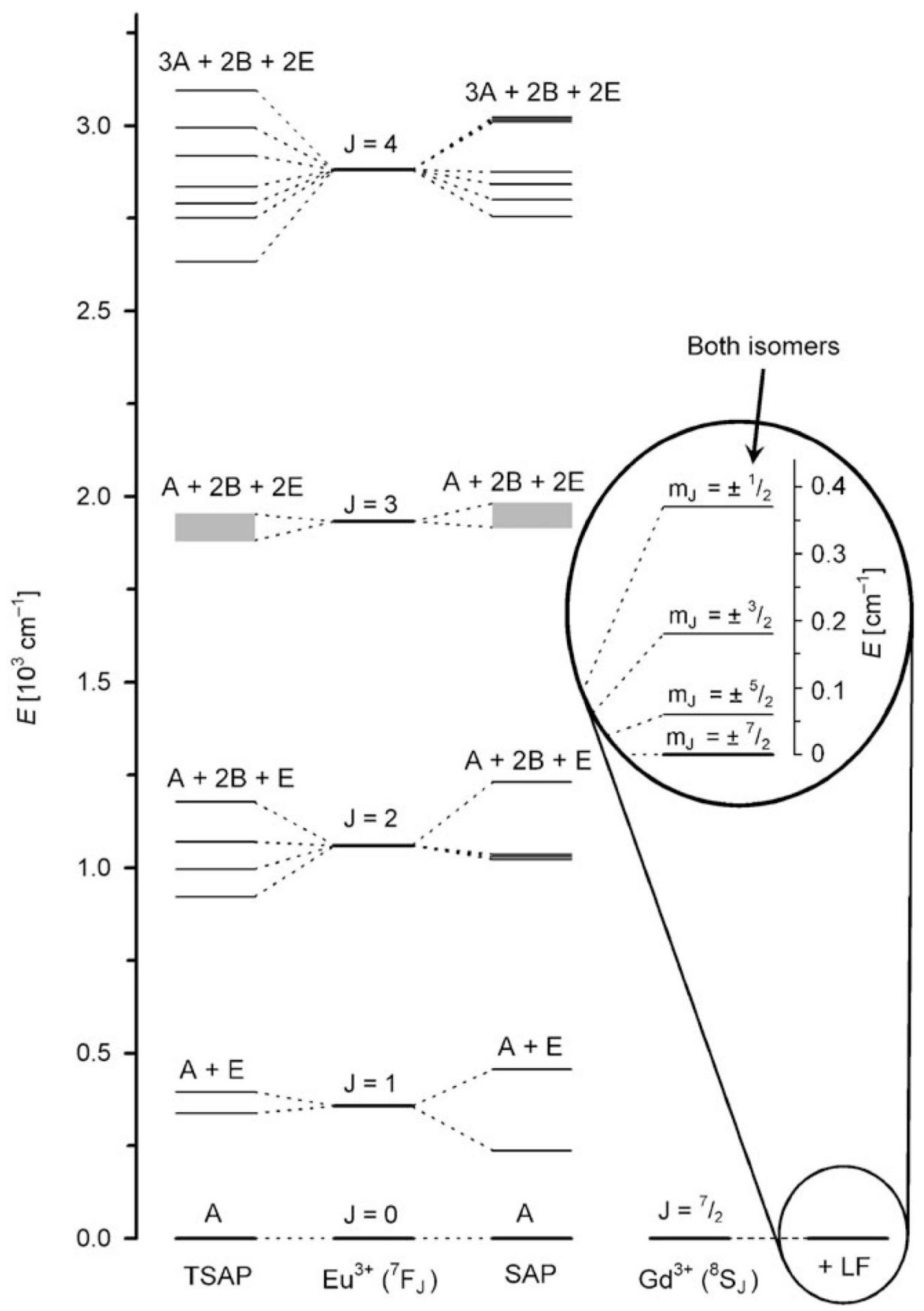

Figure 5.

The energy levels of the ${ }^{7} \mathrm{~F}_{\mathrm{J}}$ states of $\mathrm{Eu}^{3+}$ in the SAP and TSAP coordination geometries (left). The $\mathrm{J}$ states of the $\mathrm{Eu}^{3+}$ ion are shown in the centre for comparison. The energy levels of the ${ }^{7} F_{3}$ states could not be determined, the range over which those states lie is shown by a shaded region. The $\mathrm{m}_{\mathrm{J}}$ states of $\mathrm{Gd}^{3+}$ in the presence of a DOTA-type ligand field (LF) are also shown (right). Only one splitting is shown as both the SAP and TSAP isomers appear to have similar ground state splitting as observed in the $\mathrm{a}_{2 \mathrm{~T}}$ parameter of the EPR fitting. 


\section{Table 1}

Electron spin relaxation parameters obtained from fitting the EPR spectra of $\left[\mathrm{Gd}(\mathrm{S}-\mathrm{SSSS}-\mathbf{1})\left(\mathrm{H}_{2} \mathrm{O}\right)\right]^{-}$and $[\mathrm{Gd}$ $\left.(\mathrm{S}-R R R R-\mathbf{1})\left(\mathrm{H}_{2} \mathrm{O}\right)\right]^{-}$.

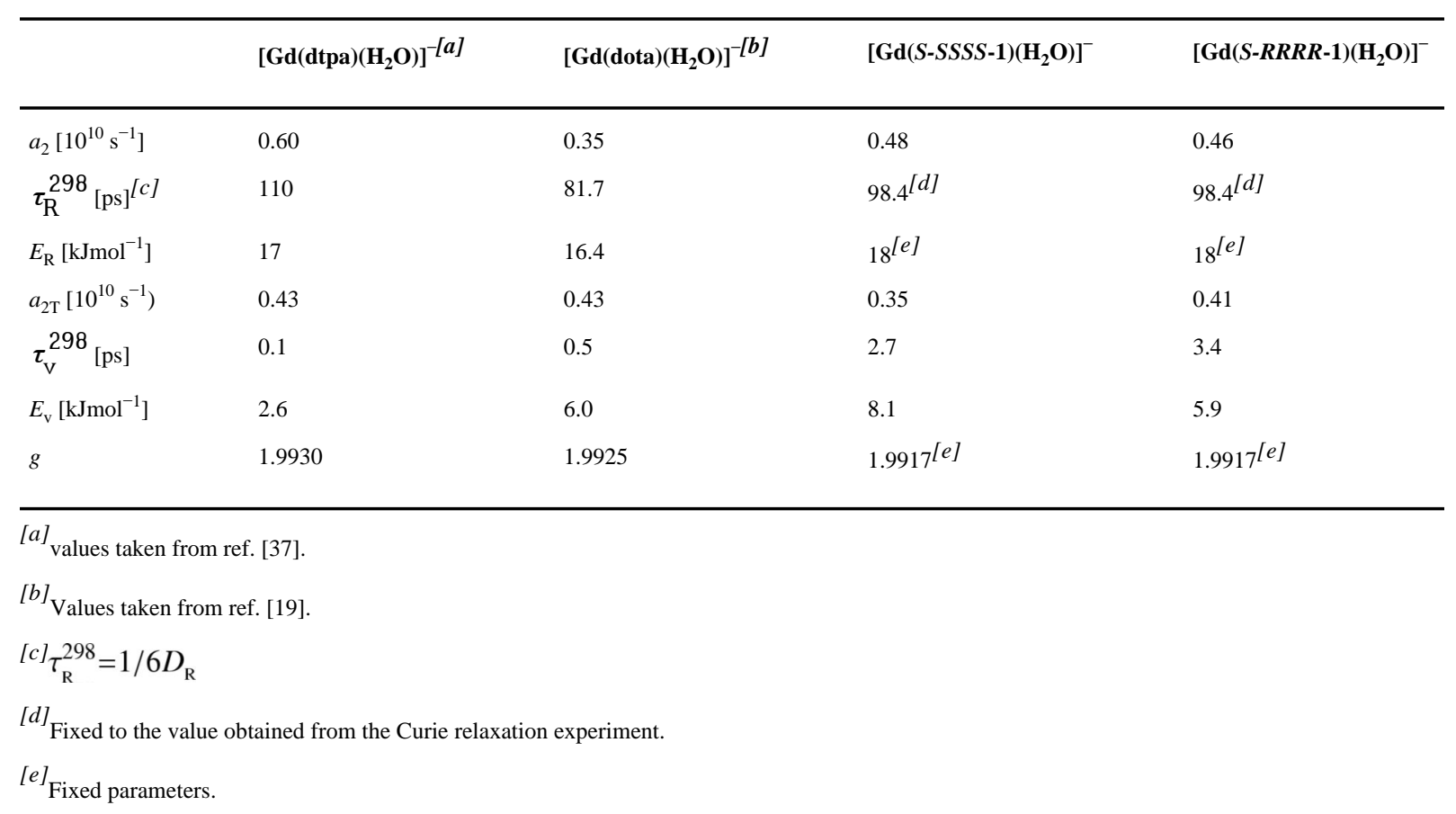

